\title{
Disposable screen printed sensor for the electrochemical detection of methamphetamine in undiluted saliva
}

\author{
Carrie-Ann Bartlett, Sarah Taylor, Carlos Fernandez, Ceri Wanklyn, Daniel Burton, Emma Enston, \\ Aleksandra Raniczkowska, Murdo Black and Lindy Murphy*
}

\begin{abstract}
Background: Methamphetamine has an adverse effect on the ability to drive safely. Police need to quickly screen potentially impaired drivers therefore a rapid disposable test for methamphetamine is highly desirable. This is the first proof-of-concept report of a disposable electrochemical test for methamphetamine in undiluted saliva.

Results: A screen printed carbon electrode is used for the $N, N^{\prime}$-(1,4-phenylene)-dibenzenesulfonamide mediated detection of methamphetamine in saliva buffer and saliva. The oxidized mediator reacts with methamphetamine to give an electrochemically active adduct which can undergo electrochemical reduction. Galvanostatic oxidation in combination with a double square wave reduction technique resulted in detection of methamphetamine in undiluted saliva with a response time of $55 \mathrm{~s}$ and lower detection limit of $400 \mathrm{ng} / \mathrm{mL}$.

Conclusions: Using a double square wave voltammetry technique, rapid detection of methamphetamine in undiluted saliva can be achieved, however there is significant donor variation in response and the detection limit is significantly higher than desired. Further optimization of the assay and sensor format is required to improve the detection limit and reduce donor effects.
\end{abstract}

Keywords: Square wave voltammetry, SWV, Galvanostatic oxidation, Screen printed electrode, Mediator, Methamphetamine, Saliva, Detection

\section{Background}

Two thirds of US trauma centre admissions are due to motor vehicle accidents with almost $60 \%$ of such patients testing positive for drugs or alcohol [1]. Cannabis, cocaine and methamphetamine are the drugs most frequently detected in drivers randomly stopped for roadside drug screening [2-5]. In Norway prior to the year 2000 there was almost no methamphetamine on the Norwegian market. There was a steady increase in methamphetamine usage till 2010 where it appeared to have stabilized. The data for this study was confirmed by testing venous blood of convicted motorists, customs seizures and wastewater analysis [6]. A US survey, using a questionnaire which annually monitored adolescent drug

${ }^{*}$ Correspondence: lindymurphy@btinternet.com

Oxtox Limited, Warren House, 5 Mowbray Street, Stockport SK1 3EJ, UK use, showed a gradual decline in methamphetamine use from $3.7 \%$ in 1981 (peak year) to $1.2 \%$ in 2008 [7]. A recent study showed conflicting trends when comparing the questionnaire survey approach and wastewater analysis. Over the period 2010-2013 the population survey showed a slight decline in methamphetamine use while wastewater analysis showed a doubling of methamphetamine usage [8].

Methamphetamine remains a significant public health concern with known neurotoxic and neurocognitive effects to the user [9]. It is frequently abused as a recreational drug due to its stimulant and euphoric effects. The physiological and psychological side effects of methamphetamine include confusion, paranoia, depression, nausea and blurred vision. Driving a vehicle while under the influence of methamphetamine is thus clearly undesirable.

\section{Springer}

(c) 2016 Bartlett et al. This article is distributed under the terms of the Creative Commons Attribution 4.0 International License (http://creativecommons.org/licenses/by/4.0/), which permits unrestricted use, distribution, and reproduction in any medium, provided you give appropriate credit to the original author(s) and the source, provide a link to the Creative Commons license, and indicate if changes were made. The Creative Commons Public Domain Dedication waiver (http://creativecommons.org/ publicdomain/zero/1.0/) applies to the data made available in this article, unless otherwise stated. 
Roadside screening for methamphetamine in oral fluid has a number of requirements: it needs to be fast, ideally 15-30 s, i.e. ideally the same speed as a breath alcohol test; it must be very sensitive, ideally $<10 \mathrm{ng} / \mathrm{mL}$ (25 ng/mL was used as the cut-off concentration in the European DRUID [Driving under the influence of Drugs, Alcohol, and Medicines] project [5]); and it should be non-invasive, difficult to tamper with and be portable. The currently available drug screening products require a minimum of 5-10 min for a test [10]. Test time and cost are restricting the roadside drug screening market to $<10 \%$ the volume of the alcohol screening market.

Oral fluid which contains saliva and other liquid substances present in the oral cavity are of great interest for roadside drug screening. Although this fluid is easy to collect there is considerable inter-sample variability in the fluid matrix that generates issues when developing a testing methodology [11]. Dilution of the sample can reduce the donor variability, however this dilutes the drug of interest and therefore requires the device to have greater sensitivity. The current devices on the market are primarily lateral flow immunodiagnostic tests, where the presence or absence of a coloured bar can be read either visually or in a meter in response to the drug of interest; these were used in the DRUID project. The response times are typically several minutes. The clinical sensitivity of these devices in saliva can be relatively poor at $16-75 \%$ although clinical specificity can be close to $100 \%$ [12].

There are only a few reports of the electrochemical sensing of amphetamines, and there are no reports of the determination of amphetamines in undiluted saliva using disposable electrochemical sensors. Electrochemical sensing of methamphetamine by direct oxidation has been reported at a pretreated pencil graphite electrode [LOD $50 \mathrm{nM}(7.5 \mathrm{ng} / \mathrm{mL})$ in aqueous solution, response time $>10 \mathrm{~min}$ ] [13], at a self-assembled boron-doped diamond electrode [LOD $50 \mathrm{nM}(7.5 \mathrm{ng} / \mathrm{mL})$ in aqueous solution, response time not given] [14], and in alkaline solution using a gold nanoparticle-multiwalled carbon nanotube modified screen printed electrode [LOD $0.3 \mathrm{nM}(0.05 \mathrm{ng} /$ $\mathrm{mL}$ ), response time not given] [15]. The indirect electrochemical detection of amphetamine in saliva has been reported using 1,2-naphthoquinone-4-sulfonate at an edge plane pyrolytic graphite electrode [LOD $41 \mu \mathrm{M}(6.2 \mu \mathrm{g} /$ $\mathrm{mL}$ ) in aqueous solution, response time not given] [16].

This paper reports a mediated screen printed carbon electrode for the detection of methamphetamine in undiluted saliva using substituted $N, N^{\prime}$-(1,4-phenylene)dibenzenesulfonamide mediator. Screen printed electrodes are well established as cheap and disposable single use sensors which can be manufactured with high reproducibility [17].

The sensor is optimized for speed of response and for response in undiluted saliva.

\section{Results and discussion}

\section{Initial mediator screen}

The mechanism of reaction between oxidized $N, N^{\prime}-(1,4-$ phenylene)-dibenzenesulfonamide and primary and secondary amines has been described by Adams and Schowalter [18]. The mechanism is shown schematically in Fig. 1. The oxidized form of the mediator (II) reacts with secondary amines such as methamphetamine (MAMP) by 1,4-addition resulting in the reduced form of the MAMP-mediator adduct (III). Electron exchange between (III) and a further molecule of (II) results in the oxidized form of the adduct (IV) which can undergo reduction at the electrode at the appropriate reduction potential i.e. it can give rise to a new reduction peak in addition to the reduction peak for unreacted oxidized mediator, (II).

With primary amines such as amphetamine (AMP), 1,2 -addition can take place, resulting in elimination of the two benenesulfonamide groups from the mediator and formation of an AMP-mediator adduct. This adduct can<smiles>CC(Cc1ccccc1)N(C)c1cc(NS(=O)(=O)c2ccccc2)cc(N(C)C(C)Cc2ccccc2)c1NS(=O)(=O)c1ccccc1</smiles>

Fig. 1 Reaction of $N, N^{\prime}$-(1,4-phenylene)-dibenzenesulfonamide with methamphetamine (MAMP) 
also undergo oxidation via II and subsequently undergo electrochemical reduction.

An initial mediator screen was performed with several substituted $N, N^{\prime}$-(1,4-phenylene)dibenzenesulfonamide compounds, described in Additional file 1 . The mediators were screened for electrochemical response using differential pulse voltammetry (DPV) and reaction with MAMP. The sensors used were of the format shown in Fig. 2a, consisting of a two electrode system of carbon working electrode and $\mathrm{Ag} / \mathrm{AgCl}$ combined counter/reference electrode. The preferred mediator was OX1006 (N,N'(2-nitro-1,4-phenylene)dibenzenesulfonamide) on the basis of giving a large, clearly defined peak response to MAMP without adsorption of the parent mediator to the electrode. At pH 10.8, the mediator is fully deprotonated [pKas 6.05 and $8.00\left(25{ }^{\circ} \mathrm{C}\right)$ ] and soluble at $1 \mathrm{mg} / \mathrm{mL}$, and this $\mathrm{pH}$ was used for the development of the sensor.

The cyclic voltammetry of OX1006 with MAMP is shown in Fig. 3. In the absence of MAMP, there is a single oxidation peak at $+0.38 \mathrm{~V}$ and negligible reduction peak. In the presence of MAMP, two new peaks are present at $+0.15 \mathrm{~V}$ and $-0.046 \mathrm{~V}$, and a new reduction peak is present at $-0.088 \mathrm{~V}$. In addition, the parent mediator peak height at $+0.38 \mathrm{~V}$ is increased by 29 and $47 \%$ in the presence of 25 and $50 \mu \mathrm{g} / \mathrm{mL}$ MAMP. The increase in the parent peak height and the new peaks are due to the oxidation/reduction of the mediatorMAMP adduct.

\section{Optimization of electrochemical procedure with dried reagent}

It was desired that the mediator and buffer solution be dried down in some way on the sensor. Deposition of

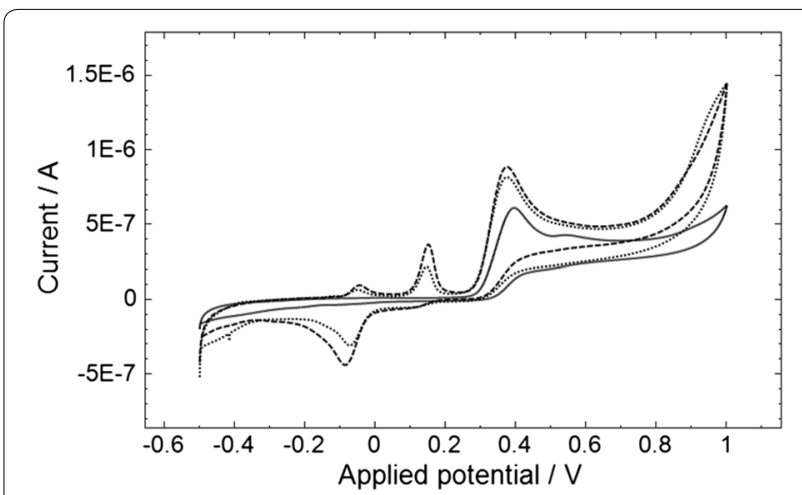

Fig. 3 Cyclic voltammetry of OX1006 in the absence and presence of MAMP. The MAMP concentration was 0, 25 or $50 \mu \mathrm{g} / \mathrm{mL}$ MAMP (solid line, dotted line and dashed lines) in $0.1 \mathrm{M}$ sodium carbonate buffer $(\mathrm{pH} 10.4), 0.2 \mathrm{M} \mathrm{NaCl} .15 \mu \mathrm{L}$ of solution was pipetted onto the sensor. The scan rate was $50 \mathrm{mV} / \mathrm{s}$

mediator solution directly onto the sensor requires tight control of the volume and position of the dispensed reagent. Therefore an alternative technique was used comprising a porous overlayer onto which mediator was dried and which is then secured over the sensor. On application of sample, the mediator dissolves and diffuses to the working electrode where it can be oxidized, react with MAMP and produce a reduction response to MAMP. Sensors with overlayer applied are shown in Fig. 2 b.

Galvanostatic oxidation of OX1006 was investigated in combination with the overlayer. The advantage of galvanostatic oxidation compared to potentiostatic oxidation is that the amount of oxidized mediator should be relatively independent of the concentration of mediator which has dissolved off the overlayer and reached the electrode surface, provided there is sufficient mediator. A
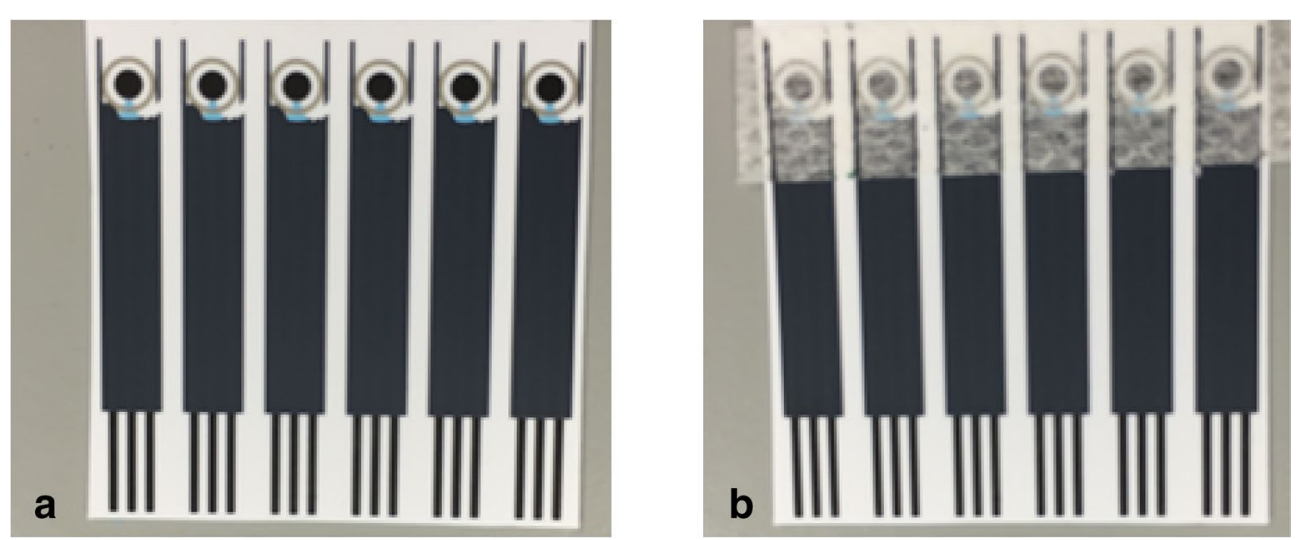

Fig. 2 Screen printed electrodes $\mathbf{a}$ without and $\mathbf{b}$ with overlayer. The sensor comprises a circular carbon working electrode (2 mm diameter) and outer $\mathrm{Ag} / \mathrm{AgCl}$ counter/reference electrode 
potential disadvantage of galvanostatic oxidation is that if there is insufficient mediator, other species present will be oxidized, resulting in a large increase in working electrode potential.

There are very few reported examples of galvanostatic oxidation to generate reactant, and these examples are for electrochemical titrations using separate generatorcollector electrodes [19, 20]. For example, Tomcik et al. [21] have reported the galvanostatic generation of hypobromite at an interdigitated microelectrode array, for end-point titration of the drugs Antabus and Celaskon. In our application, the working electrode is used to both generate the reactant (oxidized mediator) and detect the mediator-MAMP adduct.

The shift in working electrode potential during galvanostatic oxidation is shown in Fig. 4, for sensors with mediator in the overlayer and using a saliva sample. A $10 \mathrm{~s}$ wait time during which the sensor was at open circuit potential was employed at the start of the test sequence to ensure the mediator had dissolved off the overlayer. With higher galvanostatic currents there is a larger shift in potential starting at $+0.4 \mathrm{~V}$, with the shift seen at an earlier time for higher current, indicating the mediator has been depleted more quickly with higher galvanostatic current setting. A galvanostatic current of $800 \mathrm{nA}$ was selected.

The square wave voltammetry (SWV) response to MAMP in saliva buffer or saliva using galvanostatic oxidation and the mediator overlayer is shown in Fig. 5. In saliva buffer, the main reduction peak at $+0.38 \mathrm{~V}$ was reduced in the presence of MAMP (1800-1260 nA, $30 \%$ reduction), and two new peaks were observed at +0.14 and $-0.06 \mathrm{~V}$ (717 and $1430 \mathrm{nA})$. The reduction peak heights were very significantly reduced in saliva compared to saliva buffer, by approximately $85-95 \%$ (peak heights at $+0.34,+0.15$ and $-0.04 \mathrm{~V}$ were 205,38 and $88 \mathrm{nA}$ in the presence of $5 \mu \mathrm{g} / \mathrm{mL}$ MAMP). The overall response time with the SWV procedure was $122 \mathrm{~s}$. Ideally the response time of the sensor would be in the range 15-30 s, although a response time of less than $120 \mathrm{~s}$ would still be acceptable for a roadside test as it would be considerably faster than the existing roadside tests. Therefore the electrochemical procedure was optimized for speed of response.

In order to increase the speed of the SWV technique, the first part of the scan between +0.6 and $+0.1 \mathrm{~V}$ was conducted at a higher scan rate compared to the second part of the scan between $+0.1 \mathrm{~V}$ and $-0.4 \mathrm{~V}$. Both parts of the scan were optimized for amplitude, step size and frequency. The third peak height is independent of frequency (Additional file 2), therefore a faster scan rate can be used for the first part of the scan without any adverse effect on the 3rd peak height.

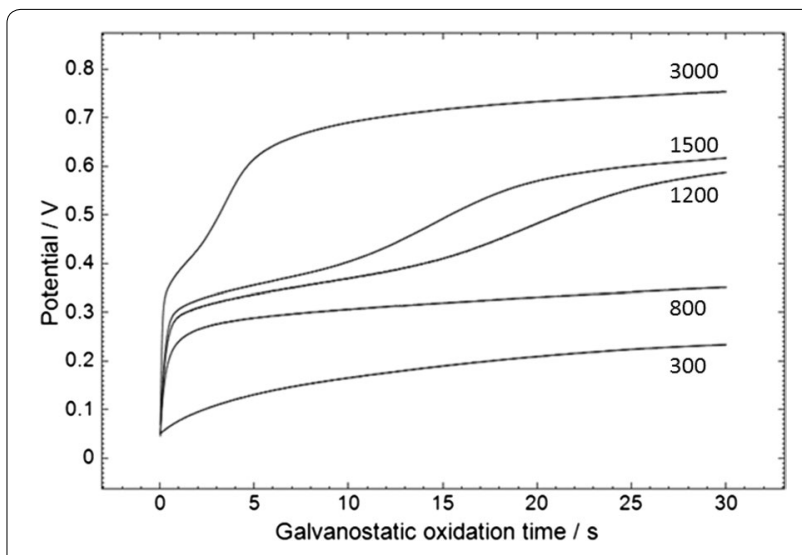

Fig. 4 Varying the current during the galvanostatic oxidation step. The overlayer was treated with $0.12 \mathrm{mg} / \mathrm{mL}$ of OX1006 in $0.4 \mathrm{M}$ sodium carbonate buffer ( $\mathrm{pH}$ 10.8), containing $0.23 \mathrm{M} \mathrm{NaCl}$ and $0.1 \%$ TX-100. The procedure consisted of a $10 \mathrm{~s}$ wait time after application of $7 \mu \mathrm{L}$ of saliva, followed by galvanostatic oxidation at $300,800,1200$, 1500 or $3000 \mathrm{nA}$ for $30 \mathrm{~s}$
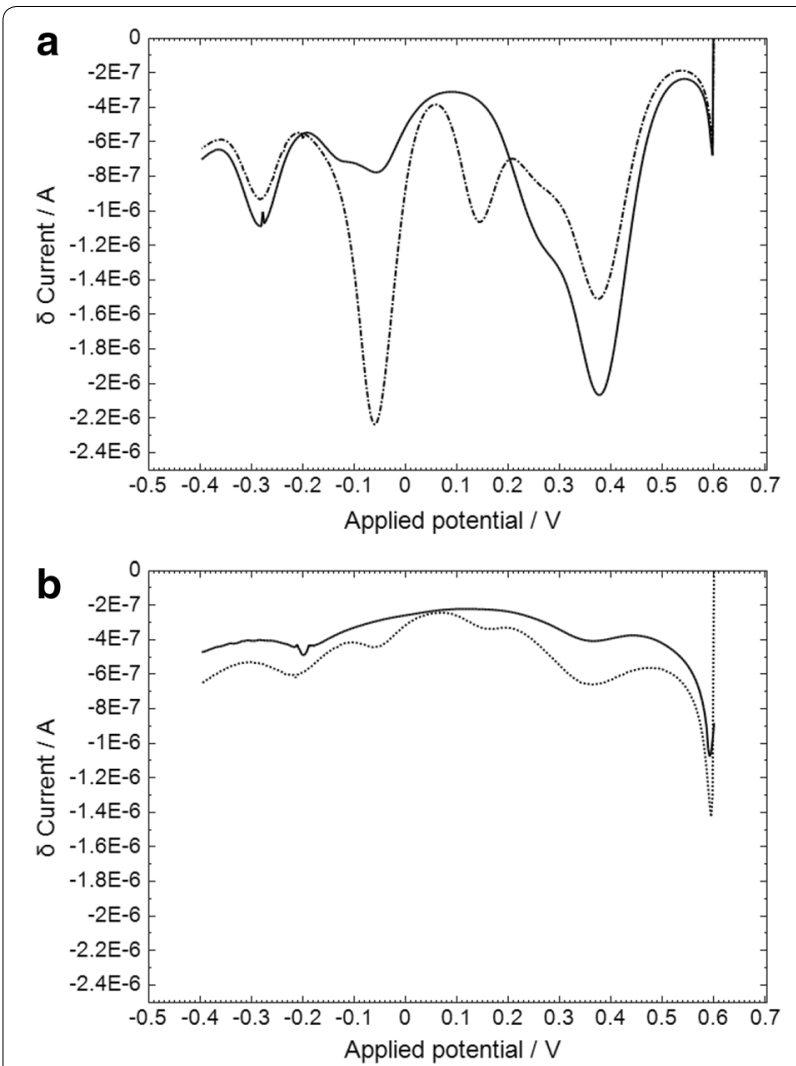

Fig. 5 SWV response to MAMP in a saliva buffer or $\mathbf{b}$ saliva. The MAMP concentration was $0 \mu \mathrm{g} / \mathrm{mL}$ (solid line) or $5 \mu \mathrm{g} / \mathrm{mL}$ (dashed line). The overlayer was treated with $1.0 \mathrm{mg} / \mathrm{mL}$ of OX1006 in $0.4 \mathrm{M}$ sodium carbonate buffer ( $\mathrm{pH}$ 10.8), containing $1.0 \mathrm{M} \mathrm{NaCl}$ and $0.1 \%$ TX-100. The SWV procedure consisted of a $10 \mathrm{~s}$ wait time after application of $7 \mu \mathrm{L}$ of sample, then (1) galvanostatic oxidation at $800 \mathrm{nA}$ for $30 \mathrm{~s}$, (2) SWV with start voltage $+0.6 \mathrm{~V}$, stop voltage $-0.4 \mathrm{~V}, 4.25 \mathrm{~Hz}$ frequency, $2.85 \mathrm{mV}$ step potential and $50 \mathrm{mV}$ amplitude 
The split SWV responses to MAMP in saliva buffer and saliva are shown in Fig. 6, using frequencies of 20 and $4.25 \mathrm{~Hz}$ for the first and second parts of the scan. The new peak in response to MAMP is clearly observed at $-0.06 \mathrm{~V}$ for saliva buffer and $-0.04 \mathrm{~V}$ for saliva. The overall response time is $55 \mathrm{~s}$. The calibration plot for response to MAMP in a saliva sample using the third peak of the optimized split SWV technique is shown in Fig. 7. Good linearity of response to MAMP was obtained $\left(R^{2}\right.$ 0.9877). The lower limit of detection was $400 \mathrm{ng} / \mathrm{mL}(0 \mathrm{ng} / \mathrm{mL}$ response $+3 \mathrm{SD})$ which is considerably higher than that required for a commercial device $(<10 \mathrm{ng} / \mathrm{mL})$.

The LOD compares favourably with that obtained using indirect electrochemistry with 1,2-naphthoquinone4-sulfonate [16], and it is considerably higher than the LODs obtained using direct electrochemical methods [13-15], although all these methods use aqueous solution and not undiluted saliva. Use of microelectrodes should provide greater sensitivity of response, since increased
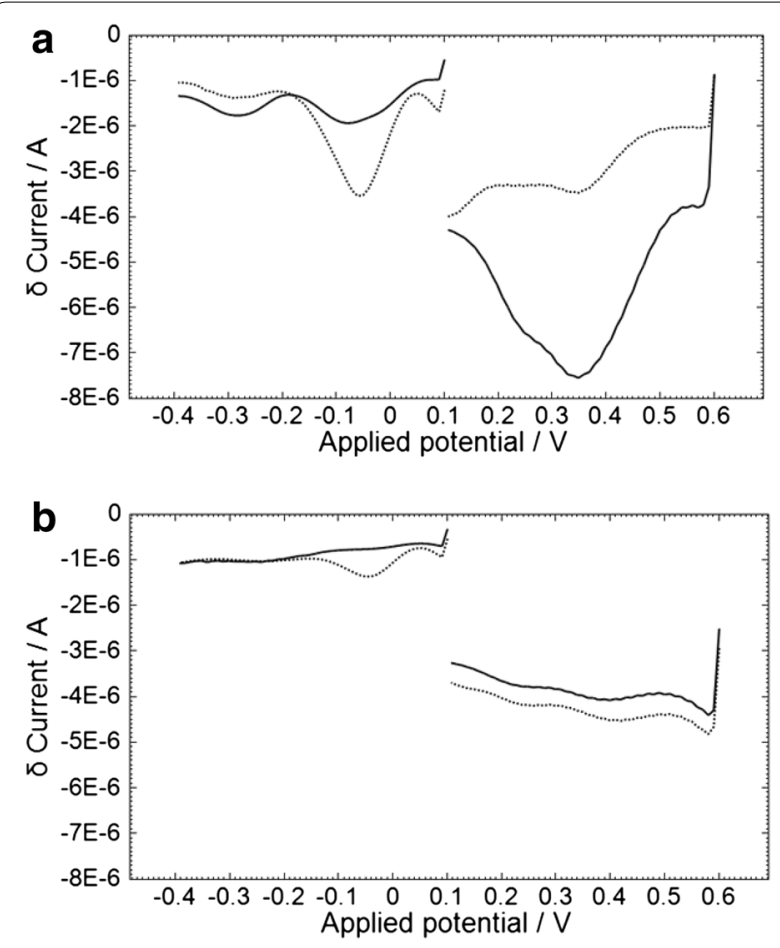

Fig. 6 Split SWV response to MAMP in a saliva buffer or $\mathbf{b}$ saliva. The MAMP concentrations were 0 (solid line) or $5 \mu \mathrm{g} / \mathrm{mL}$ (dashed line). The overlayer was treated with $1.0 \mathrm{mg} / \mathrm{mL}$ of OX1006 in $0.4 \mathrm{M}$ sodium carbonate buffer (pH 10.8), containing $1.0 \mathrm{M} \mathrm{NaCl}$ and $0.1 \% \mathrm{TX}-100$. The SWV procedure consisted of a $10 \mathrm{~s}$ wait time after application of $7 \mu \mathrm{L}$ of sample, then (1) galvanostatic oxidation at $800 \mathrm{nA}$ for $30 \mathrm{~s}$; (2) SWV-1 with start voltage $+0.6 \mathrm{~V}$, stop voltage $+0.1 \mathrm{~V}, 20 \mathrm{~Hz}$ frequency, $10 \mathrm{mV}$ step potential and $50 \mathrm{mV}$ amplitude; (3) SWV-2 with start voltage $+0.1 \mathrm{~V}$, stop voltage $-0.4 \mathrm{~V}, 4.25 \mathrm{~Hz}$ frequency, $10 \mathrm{mV}$ step potential and $100 \mathrm{mV}$ amplitude

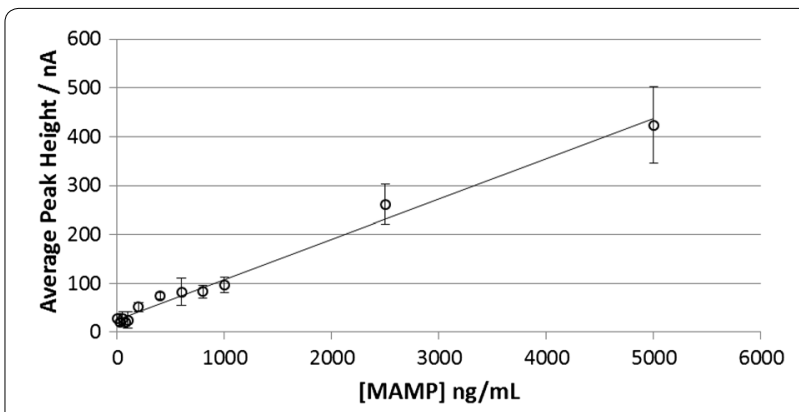

Fig. 7 Calibration plot for response to MAMP in saliva obtained from a single donor, using the 3rd peak height obtained with the split SWV technique. Each sample was tested with 12 sensors. Error bars are 1 SD. The overlayer treatment and electrochemical procedure are described in Fig. 6

mass transport of MAMP to the electrode should result in increased peak heights i.e. higher $\mathrm{nA}$ per $\mathrm{ng} / \mathrm{mL}$ MAMP. However this would require reproducible screen printed microelectrodes and development of a suitable manufacturing methodology was beyond the time and budgetary restraints of this work.

The response to MAMP and amphetamine in saliva using the split SWV technique showed a new peak formed in response to MAMP at $-0.04 \mathrm{~V}$, and no new peak observed in response to amphetamine (Additional file 3). This demonstrates the selectivity of the mediator to secondary amines over primary amines.

\section{Variation in response with different donor saliva samples}

The response to saliva obtained from 10 donors is shown in Fig. 8. There is considerable variation in 1st and 3rd peak heights, and to a lesser extent the 2nd peak height, between the donors. At $0 \mu \mathrm{g} / \mathrm{mL}$ MAMP, the average peak heights range from 95 to $1878 \mathrm{nA}$ for the 1st peak, 1523-2882 nA for the 2nd peak and $0-6 \mathrm{nA}$ for the 3rd peak. At $1 \mu \mathrm{g} / \mathrm{mL}$ MAMP, the average peak heights range from 129 to $1578 \mathrm{nA}$ for the 1 st peak, 1813-2573 nA for the 2nd peak and 0-113 nA for the 3rd peak. The individual donor samples can give very different responses. For example, while the majority of the donor samples do not show a decrease in 1st and 2nd peak heights in response to MAMP, donors 6 and 10 do show a decrease in 1st and 2nd peak heights in response to MAMP (donor 6 gave 90 and $37 \%$ decrease and donor 10 gave 59 and $30 \%$ in 1 st and 2 nd peak heights, for response to 0 and $1 \mu \mathrm{g} / \mathrm{mL}$ MAMP). However for the 3rd peak, donor 6 gave no response to MAMP, whereas for donor 10 the $3 \mathrm{rd}$ peak height increased from 2.4 to $18 \mathrm{nA}$ for $0-1 \mu \mathrm{g} / \mathrm{mL}$ MAMP. It can also be observed that only the samples from donors 2 and 8 show an increase in the 3rd peak height in 

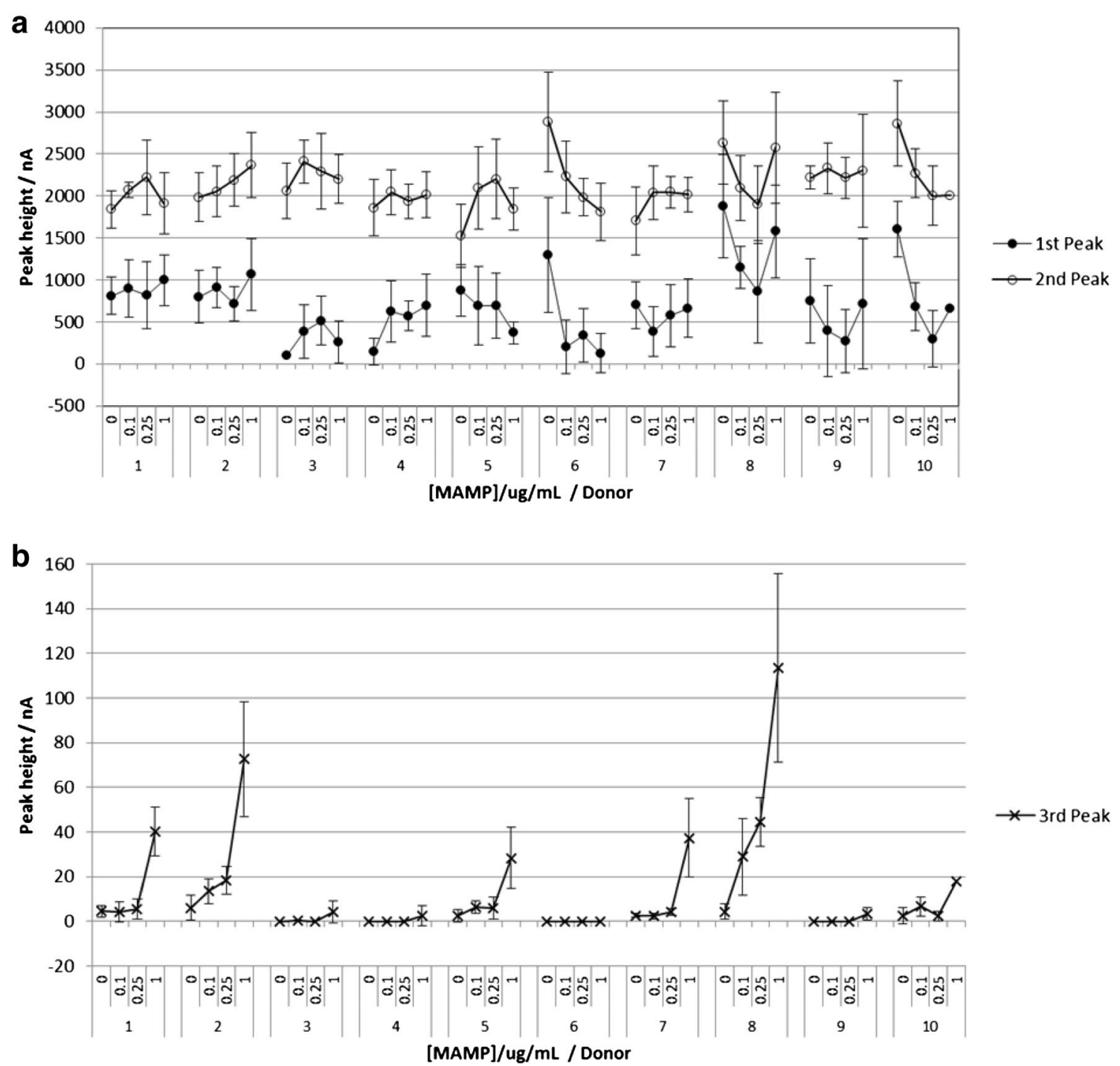

Fig. 8 Donor variation in response to MAMP in saliva from 10 donors. a 1st and 2nd peak heights and $\mathbf{b}$ 3rd peak height. The MAMP concentrations were $0,0.1,0.25$ and $1 \mu \mathrm{g} / \mathrm{mL}$. Each sample was tested with 6 sensors. Error bars are $1 \mathrm{SD}$. The overlayer treatment and SWV procedure are described in Fig. 6

response to $100 \mathrm{ng} / \mathrm{mL}$ MAMP (donor 2, 6.1-13.5 nA and donor $8,4.3-28.9 \mathrm{nA}$ for response to 0 and $100 \mathrm{ng} /$ mL MAMP).

To further investigate the effect of donor variation in saliva on response, saliva from two donors was centrifugally filtered using filters with cut-offs of 3, 10, 30 and $100 \mathrm{kDa}$. The results are shown in Fig. 9. There was a significant increase in the 2nd peak height and also in the 3rd MAMP peak height for $100 \mathrm{kDa}$ filtered saliva compared to unfiltered saliva; with $1 \mu \mathrm{g} / \mathrm{mL}$ MAMP, the peak heights increase from 218 to $629 \mathrm{nA}$ (donor 1, 2nd peak), and 15-142 nA (donor 1, 3rd peak), and from 329 to $539 \mathrm{nA}$ (donor 2, 2nd peak) and 88-285 nA (donor 2, 3rd peak). This indicates high molecular weight species such as proteins and mucin have a significant negative impact on the peak height. For donor 1, the 1st peak is not present except for the $3 \mathrm{kDa}$ filtered sample, while for donor 2 the 1st peak was not present for the unfiltered samples, but was present for the filtered samples.

The response to MAMP increased with decreasing molecular weight cut-off of the filter e.g. for donor 1, the 3 rd peak heights in response to $1 \mu \mathrm{g} / \mathrm{mL}$ MAMP were 15,142 and $353 \mathrm{nA}$ for unfiltered saliva, 100 and $3 \mathrm{kDa}$ filters. However there is still considerable donor variation in response with the filtrate from the $3 \mathrm{kDa}$ filter (the 3rd peak heights for donors 1 and 2 were 353 and 


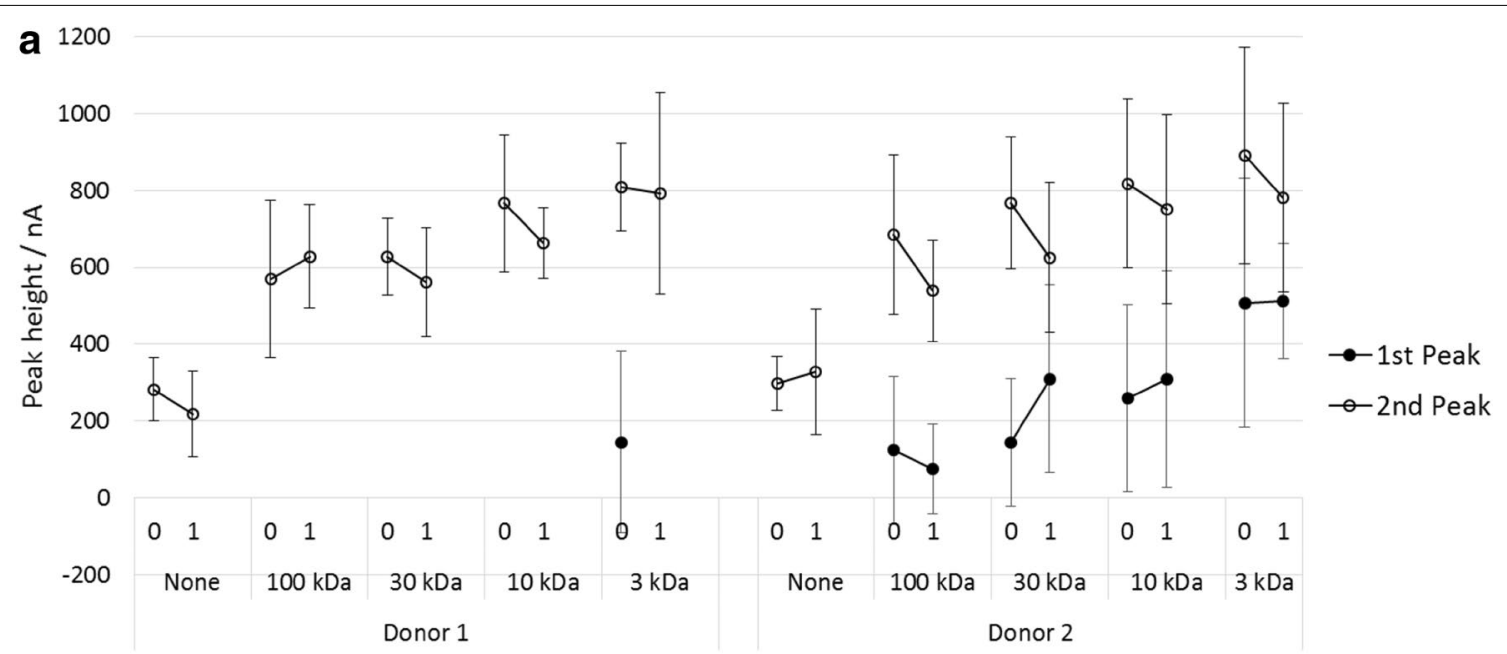

[MAMP]/ ug/mL // Filter cutoff // Donor

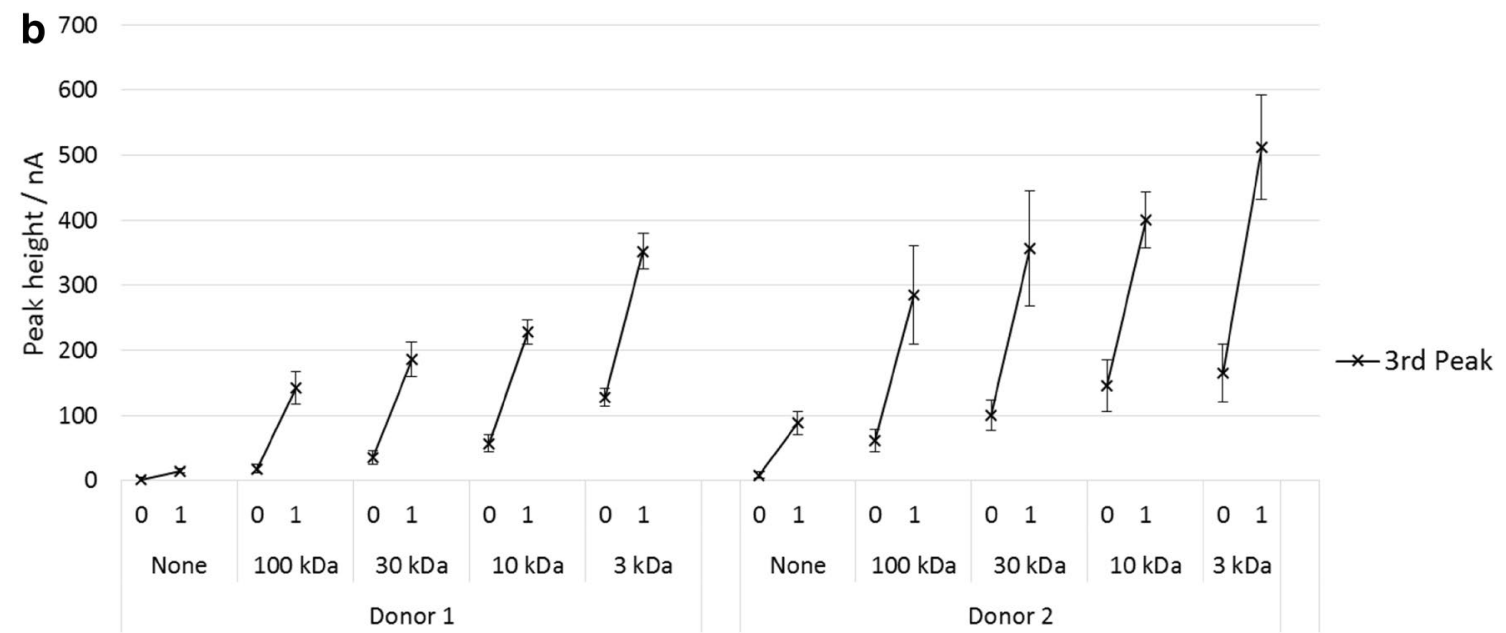

[MAMP]/ ug/mL // Filter cutoff // Donor

Fig. 9 Response to MAMP in saliva from two donors, in unfiltered saliva and saliva filtrate. a 1st and 2nd peak heights and b 3rd peak height. Saliva filtrate was collected using centrifugal filters with 3, 10,30 or $100 \mathrm{kDa}$ cut-offs. The MAMP concentrations were 0 or $1 \mu \mathrm{g} / \mathrm{mL}$. Each sample was tested with 6 sensors. Error bars are 1 SD. The overlayer treatment and SWV procedure is described in Fig. 6, except the galvanostatic current was $700 \mathrm{nA}$

$512 \mathrm{nA}$ respectively). While this filter will have removed larger proteins and mucins, some small proteins and protein fragments will remain, which may compete for adsorption sites on the electrode surface with the mediator MAMP adduct. In addition, the filtrate will contain endogenous amines which may react with the mediator.

The effect of the saliva components mucin and lysozyme on response are shown in Table 1. Addition of mucin had little effect, whereas addition of lysozyme resulted in significant reduction in peak heights, demonstrating the adverse effect of saliva proteins on response.

\section{Experimental}

(+)-Methamphetamine hydrochloride (M8750), D-amphetamine sulphate (A5880), human recombinant lysozyme (L1667) and mucin from bovine submaxillary glands (M3895) were obtained from Sigma-Aldrich Co. Ltd (Poole, UK). The mediators were synthesized by Peakdale Molecular (High Peak, UK). All other chemicals were purchased from Sigma-Aldrich Co. Ltd. All chemicals were used as received without further purification. All solutions were prepared using deionized water with resistivity no less than $18.2 \mathrm{M} \Omega \mathrm{cm}$. 
Table 1 Response to saliva buffer containing added protein

\begin{tabular}{|c|c|c|c|c|c|c|}
\hline & \multicolumn{3}{|c|}{ Average peak height/nA ( $\pm 1 \mathrm{SD})$} & \multicolumn{3}{|c|}{$\%$ Decrease in peak height } \\
\hline & 1 st peak (at $+0.40 \mathrm{~V})$ & 2nd peak (at $+0.25 \mathrm{~V})$ & 3rd peak (at $-0.06 \mathrm{~V}$ ) & 1st peak & 2nd peak & 3rd peak \\
\hline SSB & $2865 \pm 1369$ & $3257 \pm 1939$ & $436 \pm 30$ & & & \\
\hline $\mathrm{SSB}+0.021 \mathrm{mg} / \mathrm{mL}$ mucin & $2665 \pm 728$ & $2581 \pm 893$ & $481 \pm 59$ & -7.0 & -20.8 & 10.4 \\
\hline $\begin{array}{l}\mathrm{SSB}+0.021 \mathrm{mg} / \mathrm{mL} \text { mucin }+0.3 \mathrm{mg} / \mathrm{mL} \\
\text { lysozyme }\end{array}$ & $1952 \pm 1009$ & $1781 \pm 1018$ & $382 \pm 70$ & -26.7 & -31.0 & -20.5 \\
\hline $\begin{array}{l}\mathrm{SSB}+0.021 \mathrm{mg} / \mathrm{mL} \text { mucin }+3.0 \mathrm{mg} / \mathrm{mL} \\
\text { lysozyme }\end{array}$ & $985 \pm 275$ & $717 \pm 233$ & $54 \pm 29$ & -49.5 & -59.7 & -85.8 \\
\hline
\end{tabular}

(A) No addition and with the addition of (B) $0.021 \mathrm{mg} / \mathrm{mL}$ mucin; (C) $0.3 \mathrm{mg} / \mathrm{mL}$ lysozyme and $0.021 \mathrm{mg} / \mathrm{mL} \mathrm{mucin}$; and (D) $3 \mathrm{mg} / \mathrm{mL}$ lysozyme and $0.021 \mathrm{mg} / \mathrm{mL}$ mucin. The overlayer was treated with $0.2 \mathrm{mg} / \mathrm{mL}$ of OX1006 in $0.4 \mathrm{M}$ sodium carbonate buffer (pH 10.8), containing $0.23 \mathrm{M} \mathrm{NaCl}$ and $0.1 \% \mathrm{TX}-100$. Each sample was tested with 6 sensors. The SWV procedure is described in Fig. 6

Screen printed electrodes were fabricated in house with appropriate stencil designs using a DEK Horizon printing machine (DEK, Weymouth, UK). Successive layers of carbon-graphite ink (C2120403D1, modified in house by the addition of $0.1 \%$ TX-100), dielectric ink (D2070423P5) and $\mathrm{Ag} / \mathrm{AgCl}$ ink (60:40, C2030812P3) obtained from Gwent Electronic Materials Ltd. (Pontypool, UK) were printed onto a polyester substrate. The layers were cured using a tunnel drier at $70{ }^{\circ} \mathrm{C}$ (Natgraph, Nottingham, UK). The reproducibility of response of a sample of sensors from each print batch was determined using square wave voltammetry (SWV) with $1 \mathrm{mM}$ OX1006 in $0.4 \mathrm{M}$ sodium carbonate buffer $(\mathrm{pH} 10.8), 0.23 \mathrm{M} \mathrm{NaCl}$, $0.0018 \% \mathrm{TX}-100$. The SWV settings were as follows: start potential $+0.6 \mathrm{~V}$, stop potential $-0.5 \mathrm{~V}$, frequency $10 \mathrm{~Hz}$, amplitude $0.05 \mathrm{~V}$ and step size $0.00285 \mathrm{~V}$. Each sensor batch comprised 15 sheets with 4 rows of 48 sensors per sheet. A sample of 12 sensors from the second sheet of each batch were tested for SWV response to OX1006, and the responses were characterized for peak position and peak height. The \%CVs were typically in the range $0.5-1.7$ and 3-5 \% for peak position and peak height respectively.

Voltammetric measurements were performed using either a MultiAutolab M101 or a $\mu$-Autolab III potentiostat (Eco Chemie). The screen printed sensors were used as a two electrode system, with a combined counter/reference electrode (Ag/AgCl ink).

The overlayer material was composed of abaca and cellulosic fibres $(75 \%)$ in a polypropylene thermoplastic matrix (25 \%), dry weight $16.5 \mathrm{~g} / \mathrm{m}^{2}$ (CD020010, Ahlstrom) in reel format $(1 \mathrm{~cm}$ wide) was obtained from Ahlstrom (Duns, UK). The overlayer was coated with OX1006 as follows: $1 \mathrm{mg} / \mathrm{mL}$ OX1006 was prepared in $0.4 \mathrm{M}$ sodium carbonate buffer solution $(\mathrm{pH}$ 10.8) containing $1 \mathrm{M} \mathrm{NaCl}$ and $0.1 \%$ Triton $\mathrm{X}-100$. The solution was dispensed onto the membrane at a loading of $0.1-1 \mathrm{mg} / \mathrm{mL}$ and dried at $40{ }^{\circ} \mathrm{C}$. The dried overlayer was heat soldered to each sensor along the edges.

Saliva buffer, which mimics real saliva except for the absence of proteins, consisted of $27.5 \mathrm{mM}$ sodium chloride, $6.3 \mathrm{mM}$ ammonium chloride, $4.9 \mathrm{mM}$ sodium phosphate (monobasic), $2.9 \mathrm{mM}$ potassium chloride, $1.1 \mathrm{mM}$ sodium citrate (anhydrous), $0.02 \mathrm{mM}$ magnesium chloride (anhydrous), $0.27 \mathrm{mM}$ sodium carbonate and $0.2 \mathrm{mM}$ calcium chloride.

Each saliva sample was collected immediately before use by spitting into a pot. Saliva samples containing MAMP were prepared by dissolving MAMP directly into the saliva sample at $1 \mathrm{mg} / \mathrm{mL}$. Saliva samples containing lower MAMP concentrations were obtained by dilution of the $1 \mathrm{mg} / \mathrm{mL}$ sample with neat saliva.

Centrifugal filtration of saliva was performed using Amicon Ultra $0.5 \mathrm{~mL}$ centrifugal filters with molecular cut-off weights of $100,30,10$, and $3 \mathrm{kDa}$. The samples were centrifuged at $14,000 \mathrm{~g}$ for $10 \mathrm{~min}$. The filters were weighed before and after centrifugation and deionised water was added to each filtrate to adjust for volume lost.

\section{Conclusions}

The detection of $400 \mathrm{ng} / \mathrm{mL}$ MAMP in undiluted saliva has been reported using mediated disposable screen printed sensors with a response time of $55 \mathrm{~s}$. While the response time is significantly faster than existing lateral flow immunodiagnostic tests, the limit of detection of the sensors is considerably higher $(400 \mathrm{ng} / \mathrm{mL}$ compared to $10 \mathrm{ng} / \mathrm{mL}$ ) and is too high to be acceptable as a screening test. The precision of the sensor response is adversely affected by saliva proteins and further development of the sensor is required to overcome these effects and obtain a commercially viable sensor. Saliva samples are notoriously variable in terms of composition and viscosity, even within the same donor sample collected over a short period of time, and it is probable that an on-strip dilution of the sample would decrease adverse effects arising 
from sample variability and viscosity, however this would require controlled sample dilution. It would also require greater sensitivity of response which may be achieved by the use of microelectrodes and this is a route that should be investigated further. In conclusion, development of a disposable roadside test for the rapid determination of methamphetamine in undiluted saliva is challenging, and requires significant further effort.

\section{Additional files}

Additional file 1: Mediator screen.

Additional file 2: Effect of SWV-1 frequency.

Additional file 3: Response to MAMP and AMP.

\section{Abbreviations}

MAMP: (+)-methamphetamine; AMP: D-amphetamine; SWV: square wave voltammetry; DPV: differential pulse voltammetry; OX1006: N,N'-(2-nitro-1,4phenylene)dibenzenesulfonamide.

\section{Authors' contributions}

$L M$ and $M B$ co-directed the study. CF demonstrated the initial concept. EE and $A R$ characterised the electrode performance. DB and CW performed the mediator screen. CAB optimized the electrochemical procedure and ST investigated donor variation. LM and MB wrote the manuscript. All authors read and approved the final manuscript.

\section{Acknowledgements}

The authors gratefully acknowledge Professor Richard Compton and Professor Craig Banks for helpful discussions. Professors Compton and Banks are the company founders and are shareholders in Oxtox.

\section{Competing interests}

The authors declare that they have no competing interests.

Received: 7 August 2015 Accepted: 7 January 2016

Published online: 01 February 2016

\section{References}

1. Walsh JM, Flegel R, Cangianelli LA, Atkins R, Soderstrom CA, Kerns TJ (2004) Epidemiology of alcohol and other drug use among motor vehicle crash victims admitted to a trauma center. Traffic Inj Prev 5:254-260

2. Lacey JH, Kelley-Baker T, Furr-Holden D, Voas RB, Romano E, Ramirez A, Brainard K, Moore C, Torres P, Berning A (2007) National roadside survey of alcohol and drug use by drivers: drug results. National Highway Traffic Safety Administration, Washington DC. Report number DOT HS 811249

3. Van der Linden T, Legrand SA, Silverans P, Verstraete AG (2012) DUID: oral fluid and blood confirmation compared in Belgium. J Anal Toxicol 36:418-421

4. Chu M, Gerostamoulos D, Beyer J, Rodda L, Boorman M, Drummer OH (2012) The incidence of drugs of impairment in oral fluid from random roadside testing. Forensic Sci Int 215:28-31

5. Houwing S, Hagenzieker M, Mathijssen R, Bernhoft IM, Hels T, Janstrup K, Van der Linden T, Legrand S-A, Verstraete A (2011) Prevalence of alcohol and other psychoactive substances in drivers in general traffic. Part I: general results. DRUID Deliverable 2.2.3. www.druid-project.eu
6. Bramness JG, Reid MJ, Solvik KF, Vindenes V (2015) Recent trends in the availability and use of amphetamine and methamphetamine in Norway. Forensic Sci Int 246:92-97

7. Johnson LD, O'Malley PM, Bachman JG, Schulenberg JE (2008) Monitoring the future. National results on adolescent drug use. Overview of key findings, 2008. (NIH Publication No 09-7401). National Institute on Drug Abuse, Bethseda

8. Tscharke BJ, Chen C, Gerber JP, White JM (2015) Trends in stimulant use in Australia: a comparison of wastewater analysis and population surveys. Sci Total Environ 536:331-337

9. Courtney KE, Ray LA (2014) Methamphetamine: an update on epidemiology, pharmacology, clinical phenomenology, and treatment literature. Drug Alcohol Depend 143:11-21

10. Alere Toxicology. https://alere.app.box.com/s/5y3fu2mbw06lpcsi7fa4

11. Chiappin S, Antonelli G, Gatti R, De Palo EF (2007) Saliva specimen: a new laboratory tool for diagnostic and basic investigation. Clin Chim Acta 383:30-40

12. Vanstechelman S, Isalberti C, Van der Linden T, Pil K, Legrand SA, Verstraete AG (2012) Analytical evaluation of four on-site oral fluid drug testing devices. J Anal Toxicol 36:136-140

13. Oghli AH, Alipour E, Asadzadeh M (2015) Development of a novel voltammetric sensor for the determination of methamphetamine in biological samples on the pretreated pencil graphite electrode. RSC Adv 5:9674-9682

14. Svorc L, Vojs M, Michniak P, Marton M, Rievaj M, Bustin D (2014) Electrochemical behaviour of methamphetamine and its voltammetric determination in biological samples using self-assembled boron-doped diamond electrode. J Electroanal Chem 717-718:34-40

15. Rafiee B, Fakhari AR, Ghaffarzadeh M (2015) Impedimetric and stripping voltammetric determination of methamphetamine at gold nanoparticles-multiwalled carbon nanotubes modified screen printed electrode. Sens Actuators, B 218:271-279

16. Goodwin A, Banks CE, Compton RG (2006) Tagging of model amphetamines with sodium 1,2-naphthoquinone-4-sulfonate: application to the indirect electrochemical detection of amphetamines in oral (saliva) fluid. Electroanal 18(18):1833-1837

17. Thiyagarajan N, Chang J-L, Senthilkumar K, Zen J-M (2014) Disposable electrochemical sensors: a mini review. Electrochem Commun 38:86-90

18. Adams R, Schowalter KA (1952) Quinone imides. X. Addition of amines to p-quinonedibenzenesulfonimide. JACS 74:2597-2602

19. Rajantie H, Strutwolf J, Williams DE (2001) Theory and practice of electrochemical titrations with dual microband electrodes. J Electroanal Chem 500(1-2):108-120

20. Rajantie H, Williams DE (2001) Potentiometric titrations with dual microband electrodes. Analyst 126:1882-1887

21. Tomcik P, Krajcikova M, Bustin D (2001) Determination of pharmaceutical dosage forms via diffusion layer titration at an interdigitated microelectrode array. Talanta 55:1065-1070

\section{Submit your manuscript to a SpringerOpen ${ }^{\circ}$ journal and benefit from:}

- Convenient online submission

- Rigorous peer review

- Immediate publication on acceptance

- Open access: articles freely available online

- High visibility within the field

- Retaining the copyright to your article

Submit your next manuscript at $>$ springeropen.com 